\title{
A Study on the Information-Merged-Education in Paochung Elementary School, Taiwan
}

\author{
Shu-Mei Wang \\ School of Economics \& Management \\ Fuzhou University \\ Fuzhou, China \\ p6220421@gmail.com
}

\begin{abstract}
The purpose of this research is to inherit and preserve the local culture Dabu Flower-Drum Dancing Array by establishing a useful informational teaching program to be implemented into the local education curriculums Baojhong Elementary School at Baojhong Village Yunlin County was selected as the sample school to conduct this research, which is carried out since September 2002, lasted for an academic year. The author applied a 20-week designed teaching program on 40 students, who are specifically appointed for this research. The conclusions obtained from this action research are: 1. Offering the learning opportunities for heterogeneous students. 2 . Enhancing the teaching efficiency by providing this program to those educators without experience 3.Inspiring student's learning motivation and providing educators a multiple teaching methods. 4. Promoting the popularity of the Dancing Arts by integrating it with the informational education system.
\end{abstract}

Keywords: Dabu Flower-Drum ・Information Merged Education • Action Research

\section{Introduction}

The $21^{\text {st }}$ century is an era of information technology. With the prevalence of World Wide Web, the way people communicate has experienced a profound change. Meanwhile, the internet makes online learning, a possible option for today's students and plays an important role in increasing teaching efficiency. Besides, by using online teaching materials, students' learning motivation can be stimulated

Education is a important part of the society, it is not only significantly influenced by the society, but can impact the development of society. Therefore, with the advance of science and technology in today's society, we have to pay more attention to education. Moreover, along with the development of media, appreciating the diversity of different ethnic cultures is becoming the mainstream of the $21 \mathrm{st}$ century.

\section{A. Research Background}

Baojhong Elementary School was selected to develop the seeded school for the primary "Reserved Information", in Project for "Implementation and Training for the Informational Seeded School and Educator Team - 2002" by Ministry of Education Taiwan, R.O.C.. Huang Ding Kuo, present principal of Baojhong Elementary School, assigned this kind of dance as the theme of this project. In assist of the informational teaching materials, he expected that the traditional Dabu Flower-Drum Dance can be inherited and preserved.

Dabu Flower-Drum Dancing Array is a traditional form of dance in Baozhong Village Yunlin County. In September, 2001, it represented Taiwanese traditional folk art to perform at the opening ceremony of Cultural City Asia held in Taipei. This kind of dance is a mixture of art and Taiwanese's everyday life. Its uniqueness, originality, diversity, internationality make it a pride of Taiwan. As educator of Dabu Flower-Drum Dance, we have to take responsibility to carry forward our traditional culture.

B. Research Objectives

Based on the research background, the purpose of this study is as follows:

1) Design a set of informational teaching materials ,which allows learners to learn without the constraints of time and space .

2) Through this project, resources from school administration and our teaching team can be integrated and teachers will be motivated to make progress .

3) By passing the Project for "Implementation and Training for the Informational Seeded School and Educator Team - 2002", to upgrade Baozhong Elementary School to seeded school for the intermediate "Reserved Information".

\section{Research scope and limitations}

For researchers, there is no information about action education teaching material, therefore, the development of Dabu Flower-Drum Dance teaching module, is a task which starts from scratch. Moreover, in the research process, research objects are limited to pupils in grade three taught by researchers of this project. Hence the scope and limitations of this study are listed as follows:

1) The teaching materials of this study are mainly on Dabu Flower-Drum Dance, and it targeted on elementary school grade three students; other grades' students and different flower drum dancing array would not be included in this study.

2) Although this study is an accessorial teaching material for the development of computer information, it does not involve introductions on technical aspect. Only the process of teaching with this teaching material is discussed.

3) Although without professional knowledge on Internet Technology, researchers of this study are rather 
experienced professional dance instructors. Therefore, the results of this study may not represent the general teaching result of dance instructors due to their difference of ability.

\section{Literature review}

This section is to discuss topic related literature, including Dabu Flower-Drum Dancing Array's origin, movements, costumes and the use of Internet in teaching, etc.

\section{A. The Origin and Development of Flower-Drum Dancing}

Array

Flower-Drum Dancing Array appeared in around 1961. At that time, Zhen'an Temple in Baozhong township Yunlin County was holding a grand festival and believers all over Taiwan made a pilgrimage to visit it. Meanwhile, there were a lot of different Din-Tao (the leader of the parade) performances, which caught Cheng-Yu Lin's attention. Lin found it is interesting and formed a team with some of his friends to practice the Din-Tao performance. At the beginning, they only practiced for fun. However, there was a chance to go on a pilgrimage to Baigeng Chao-Tien Temple with other three villages. The village head asked Lin to form a Din-Tao performance team in order to bustle the festival. Therefore, Lin and his friends formed the team and named it as Flower-Drum Dancing Group.

Lin recalled that he was good at dancing then. At that time, they only have a gong, a small drum, two umbrellas and a small head flag. Most of the Din-Tao dancers are young children, who danced in a fast tempo. I was afraid that we would not be able to catch their dancing tempo; therefore, I made some changes of the dance. Before long, we could do the dance. My wife used the bed sheets with flower patterns to make the dancing costume. Besides, the drums that we played also decorated with flowers. This was the reason that I named the team as "Flower-Drum Dancing Group". Then I changed the name to "Flower-Drum Dancing Array" four or five years later.

\section{B. Dance Properties in Flower-Drum Dancing Array}

Drum: It is tied to the drummer's chest with a drum towel.The drummer controls the tempo of the dance team.

Small gong: is a vibration instrument, which is made of copper, hit the gongs with a hammer to generate voice.

Head flag: a triangle flag, with delicate dragon patterns and tassels. At the top of the flag, there is a metal spear, beneath the spear, there is a red cotton flower. The head flag is the soul of the dance properties.

Umbrella: was used to block the sun when the king was on their Tour of Inspection in ancient times. During the performance, the performer who holds the umbrella must keep the umbrella spinning.

Cymbals: is made of copper, it is a kind of vibration instrument.

\section{Introduction of Flower-Drum Array Formation}

Formation and posture are significant elements of the Flower-Drum Dance. To perform in an orderly way, every movement should be on the drumbeat.

1) Formation of Male Drum Team

(a) Worship gods: The drummer start the drums and gongs, and lead the whole team to the worship gods in the temple

(b) Dragon marching: Led by a leader, the team marched forward in $\mathrm{Z}$ line

(c) Dragon grabs beads(Hurrah): The team surrounded the head flag and gathered to the center and sing "Hurrah" while the leader lifted the flag.

(d)Pattern " 8 ": Performers formed a circle, the leader, with a flag, walked through the margin of the parade on his opposite side, followed by his teammates. In this way, the parade formed a pattern similar to the number 8 .

(e) Spiral: Led by the team leader, performers gathered to the center of the circle. While reaching the center, the team retreated to their former position, meanwhile, the leader waved the flag to signal his team to perform basic dance movements.

(f) Blooming flowers: the team started from a circular formation, while the flag was moving to the center, four Umbrellas would respectively move to the center. Performers who held the umbrellas also took a bow while marching. Meanwhile, gong and cymbal performers sat down and played their instruments

\section{2) Formation of Female Drum Team}

(a) Three flowers: The female performers started from a circular formation, after a whistle and a flag wave, four cymbals, four umbrellas with flags and drums gathered together to form a new formation.

(b) Two rows exchange: Changed the formation from two lines into three lines. The drummer and standard-bearer were at the center, while other performers stood beside them. After a whistle and a flag waved, the drummer and standard-bearer exchanged their positions. Meanwhile, the act of exchanging positions was performed by the performers who held the umbrellas and the gong players and drummers, as well.

(c) Double circle: After the completion of the basic formation, the standard-bearer, drummer and performers with umbrellas moved towards the center. After a whistle, performers with umbrella exchanged positions and then retreated to their former positions. After each position changed, drum and gong would play to increase momentum.

(d) Cross shape: This formation derives from the basic circular formation. While the standard bearer signals with a whistle, the standard-bearer, drummers and umbrella holders moved to the center to form a cross-shaped formation. Then, after another signal, the whole team started the gongs and drums together.

(e)The gathering: All the performing properties were gathered together in a circle. After a whistle, four gong players marched to the center to meet with other gong players. Followed by that, the cymbal players, drummers, standard-bearer gathered together.

(f) The threading: Threading formation was like to thread a needle. The head flag led the team as a straight line. When the head flag whistled and waved the flag, it would make a back turn and go through between gongs and cymbals. Following this movement, gongs, and cymbals made a back 
turn in order and did the same movement as the head flag. The other performers that head flag had not passed through would sway forward in small steps and waited for the head flag to go through. When the head flag passed the last performer, the whistle blew and changed to next formation.

\section{The basic movements of Flower-Drum Dancing Array}

1) Flag worshiping:Head flag led the entire team divided into three rows to the square. Head flag and drums in the middle, the other gongs, cymbals, and umbrellas stood on both sides evenly. The head flag lifted the flag flat as high as shoulder, then right foot stepped forward as forwarding lunge and swung flag up and down three times then stands up.

2)Moving forward with bending legs: Leaning the body forward about 15 degrees, then stretching the right leg outward with the inner foot touching the ground. At the same time, bending the left leg. Moving forward while the right leg was stretching outward and exchanging from left to right according to the rhythm.

3)Moving backward with poking soil posture: Moving backward with the body leaning back slightly, and feet moved inside as poking soil. Both feet did the same movement in turns according to the rhythm. This gesture looked like poking the soil when people plant peanuts. The performers of flag, gongs, cymbals and drums all stayed in the same movement.

4) Swaying: To show the strength and beauty by swaying the body. Flags, gongs, and flags swayed in the same way. When crossing the right foot, hip goes right, and the center of gravity located on the right feet. Then moved left, so that hips swayed.

\section{E. Costumes and the number of performers of Flower-Drum Dancing Array \\ 1)Costume:}

(a) Male drum team: The costume of Baozhong Flower-Drum Dancing Array was designed and made by Lin's wife whose job is a clothes maker. In order to distinguish the differences from Drum Dancing Array and be able to feature the highlights of temple festival, she chose flowery clothes for performing costumes. She used the simple flower bed sheets, put it on the performers and go with the white pants (unique and avoiding firecrackers) or shorts (better for performers to perform). Thus, complete the design of male team's costume.

(b). Female drum team: To be different from the male team, Su-Fung Guo, Zhang-San Qi and Shu-Rui Yang spent a lot of time and finally found the clothes in Dihua Street in Taipei and completed the design and making of female team's costumes, including bamboo hats, flowery clothes and embroidered shoes, etc.

(c)The number of performers: There are 14 performers in the Flower-Drum Dancing Array, which consists of one head flag, one drum, four umbrellas, four gongs, and four cymbals. In order to enhance the performance, sometimes they will increase the number of performers, but no more than eighteen.

\section{$F$. A study of information integration teaching}

In this chapter, the meaning and advantage of information integration teaching are discussed:

1) The meaning of information integration teaching
In a broad sense, teaching materials and activities on the computer are defined as information materials. Currently, these kinds of teaching materials are from Web-Title[1].Web-Title designs and puts teaching materials on the internet to provide access to users to learn. [2]

2) The advantage of information integration teaching To apply information technology to teaching, the first thing is to understand what role information technology should be in teaching. Dwyer [3] proposed the following four points of view:

(a)Information technology can help students acquire knowledge without considering the limitation of time and space.

(b)It allows us to expand our learning community.

(c)It can provide students acquisition restructuring and organization of ideas and experiences which can help students build their perspective on how the world works.

(d)Information technology can provide a tool to develop a faithful reader group, regardless of the distance.

3)The comparison of information learning environment and traditional learning environment, which is shown in Table 1.

Table 1 The comparison of information learning and traditional learning environment

\begin{tabular}{|c|c|c|}
\hline & $\begin{array}{l}\text { Information learning } \\
\text { environment }\end{array}$ & $\begin{array}{l}\text { Traditional learning } \\
\text { environment }\end{array}$ \\
\hline Place & $\begin{array}{l}\text { Learner can access to a } \\
\text { computer system to learn } \\
\text { in any places }\end{array}$ & $\begin{array}{l}\text { Instructor and learner } \\
\text { have to be at the } \\
\text { same place }\end{array}$ \\
\hline $\begin{array}{l}\text { Interpersonal } \\
\text { Communication }\end{array}$ & $\begin{array}{l}\text { Provide real-time and } \\
\text { non-real-time } \\
\text { multivariate } \\
\text { communication channel }\end{array}$ & $\begin{array}{l}\text { Only be able to } \\
\text { interact face to face }\end{array}$ \\
\hline $\begin{array}{l}\text { Teaching } \\
\text { Information }\end{array}$ & $\begin{array}{l}\text { Have extensive learning } \\
\text { resources, with } \\
\text { interactive, convenience, } \\
\text { and diversity }\end{array}$ & $\begin{array}{l}\text { Restricted to existing } \\
\text { information } \\
\text { resources, more } \\
\text { difficult to obtain and } \\
\text { present }\end{array}$ \\
\hline Teaching Courses & $\begin{array}{l}\text { Information media with } \\
\text { high interactivity and } \\
\text { immediacy can be } \\
\text { updated at any time }\end{array}$ & $\begin{array}{l}\text { Less likely to interact } \\
\text { and change }\end{array}$ \\
\hline $\begin{array}{l}\text { Learning } \\
\text { Community }\end{array}$ & $\begin{array}{l}\text { Smooth communication } \\
\text { channel and equal status } \\
\text { between instructors and } \\
\text { learners }\end{array}$ & $\begin{array}{l}\text { Easily lead to } \\
\text { communication } \\
\text { difficulties caused by } \\
\text { authoritarianism }\end{array}$ \\
\hline
\end{tabular}

\section{Research Method}

In this study, information is integrated into local culture teaching. Meanwhile, an informational teaching material is designed in order to help students understand the course content. To conduct this research, experts, scholars and members of the organization cooperated with each other. In this way, the problem has been developed into a research topic for a systematic study. Teachers, who are researchers of this study managed to research on the problem with the assist of researchers. Therefore, in this research, the teaching process has become the core of education, which will shorten the educational theory.

\section{A. Researcher background}

Researcher of this study who has sufficient experience in dance education, graduates from Department of the dance of 
Tainan women's University of science and technology, and has a deep understanding on Dabu Flower-dance. Therefore, the researcher has been assigned to design teaching plans for this project.

B. The research model of information integrating into

A. Conclusion

\section{Conclusion and Suggestions}

In order to adjust to computer teaching, teaching material should not only include skill acquisition but also consider the pattern of computer language and convenience of study without time and space limitation. Therefore, teaching material designers should design materials which can cater a variety of different learning needs of students. Furthermore, this teaching material can not only provide dance instructors without sufficient experience on teaching but also offer students opportunities to observe dance movements. By teaching via the Internet, students learning motivation can be stimulated; meanwhile, it offers teachers a wider range of teaching methods. Nowadays e-learning has already become a trend.Combining dance art with internet education can promote the popularization of dance education.

\section{B. Suggestions}

According to the research result, there are some suggestions for educators, administrators, and dance teaching.

\section{1) Education and administration:}

(a) More attention should be drawn to local culture, and more information technology courses should be provided to improve teachers teaching proficiency.

(b) The County Bureau of Education Advisory Group should pay more visits to campus, to provide advice.

(c) In making local information materials, the government can develop a set of information materials for teachers.

\section{2) Teaching}

(a)To improve teacher's information competence, they have to attend capability tests to improve their teaching quality.

(b) In accordance with the expertise of present teachers in the school, a teaching team should be formed to research and develop a set of information materials.

\section{References}

[1] Chen Liru, He Ronggui, Web-Title User Interface Design. Journal of Information and Education, 64, 21-64. (1998)

[2] Big flower drum Township situation,Times Cultural Education Foundation, Qing-Yun, Zhang. (1997).

[3] David, C. Dwyer. Since computers came to school. Educational Technology, 42(4), 17-18. (2002).

[4] Nien-Hsing, Chen, Integrated Learning Environment. April 4, 1991, From: http://www.ntu.edu.tw/TANET97/IT/t067/. (1997)

[5] Ming-Chou, Hung, Computer - mediated Communication and Teaching Innovation in Higher Education, Journal of Taibei Teachers College,11,34. (1998).

[6] Know the Dabu, Yunlin County Baozhong Township Big Flower education

This study focused on Da-Bu Flower-drum teaching with computer information technology. The research model is shown in the diagram.

Drum Culture Promotion Association.(1999)

[7] Chun-Nan, Tsai, A Study on the Teaching Willingness of Primary and Middle School Teachers Using Information Facilities in Kaohsiung City, National Institute of Industrial Science and Technology Education, Kaohsiung Normal University,Kaohsiung City.(2000).

[8] Chuan-Shih,Wang, Significance and Connotation of the Integration of Information Technology into TeachingInformation and Education,80,24-27. (2000)

[9] Tsung-Wen,Cheng, Cooperative Learning and Problem Solving Cultivating Problem - Solving - Oriented Cooperative Learning.Information and Education, 85, 57-61.. (2001).

[10] En-Chia, Liang, A Study on the Influence of Dagang Huagux Zhen on Residents' Community Awareness and Community Development, Chung Cheng University Adult and Continuing Education Institute, (2002).

[11] Yunlin County Government, Ma Mingzhen five-year-old Chitose Culture Festival album. (2003)

[12] Mojgan, H, Effectiveness of integration of internet technologies in support of teaching and learning computer science programming, Oregon State University, Oregon. (2001) 